\title{
O Novo Direito do Mar e a América Latina*
}

\author{
Vicente Marotta Rangel \\ Catedrático de Direito Internacional Público \\ da Faculdade de Direito da Universidade de \\ São Paulo.
}

Sumário: I. A Gênese do Direito do Mar e o Continente Americano. II. $A$ Codificação do Direito do Mar. III. $O$ Princípio da Liberdade dos Mares e a América Latina. IV. 4 Nova Dimensão do Direito do Mar. V. O Alargamento da Jurisdição Horizontal do Estado Costeiro. VI. Os Fatores e o Processo. VII. Consideracōes Finais.

\section{A Gênese do Direito do Mar e o Continente Americano}

0 direito do mar, em sua expressão clássica, é produto de um processo gradual de elaboração e consolidação de normas regulamentadoras dos espaços oceânicos, o qual teve curso entre os séculos XVI e XIX, embora possa remontar, episodicamente, mesmo ao século XIII, quando se delineou, entre cidades italianas assim como ao norte da Europa, a distinção entre districtus e pelagus, entre águas territoriais e alto-mar ${ }^{1}$.

Com o advento do período das grandes descobertas, e do processo de crise de Direito do Mar que delas resultou, rivalizaram-se, como se sabe, duas diretrizes fundamentais. As que se defrontaram na polêmica dos mares ${ }^{2}$, reunindo, entre outros,

* Comunicação apresentada às "Primeras Jornadas Latino-Americanas de Derecho Internacional", organizadas pela Universidad Católica Andrés Bello (Caracas, 1978).

1. Raestad, Arnold. La Mer Territoriale. Paris, Pedone, 1913, pp. 20 $\theta$ segs.

2. Vide NYs, Une Bataille de Livres, in Etudes de Droit International et de Droit Politique, Dewxième Série, Bruxelas-Paris, 1901, pp. 260/272; idem, Les Origines du Droit International, Bruxelas-Paris, 1894, pp. 379-387; GarciA ARIAs, Historia del Principio de la Libertad de los Mares, Santiago de Compostela, 1946; Fulton, The Sovereignty of the Sea, Edimburgo, 1911, pp. 1-56; 
de um lado, nomes como os de Gentilis, de WeLwood, de SELDEN, de MEDOWS, de SERAFIM de FREITAS; de outro lado, os de Vitória, de MenchaCA, de Grócio ${ }^{3}$.

A primeira dessas diretrizes propendia para a justificação do monopólio dos oceanos; ou, a rigor, o admitia, ampla e irrestritamente. Conquanto se qualificasse o mar entre as res communis omnium, e se declarasse ser ele comum quanto ao uso e nullius com respeito à propriedade, se ponderava que, no tocante à jurisdição, estava o mar sujeito à Coroa: sed jurisdictio est Caesaris. Águas do Imperador, assinala GARCIA ARIAS, ${ }^{4}$ eis como se designava o alto-mar com freqüência no século XVI. Daí a posição das Coroas portuguesa e espanhola em reivindicarem a jurisdição sobre os oceanos. E em relação aos mares que então se descobriam, não apenas a jurisdição senão também o domínio exclusivo ${ }^{5}$, que as bulas de ALEXANDRE vi contribuíram para consagrar: Eximiae Devotionis e Inter Cetera, de 3 de maio de 1943; a segunda bula Inter Cetera, do dia seguinte; e Dudum Siquidem, de 26 de setembro do mesmo ano. Parte dos desentendimentos, que ainda subsistiam ${ }^{6}$ na relação entre os dois Estados, se diluiu nos termos do Tratado de Tordesilhas, de 7 de junho de 1494, confirmado a 2 de julho e a 5 de setembro do mesmo ano, respectivamente em Arévalo e em Setúbal, pelos reis católicos e por D. João II. Essa mesma orientação monopólica perfilharam, com redobrado empenho, os governantes da Inglaterra, no século XVII. Culminou ela com as conhecidas exigências da saudação ao pavilhão, de que batalhas navais resultaram. ${ }^{?}$

GIDEL, Le Droit International Public de la Mer, III, pp. 127 e segs.; RIESENFELD, Protection of Coastal Fisheries under International Law, Washington, Carnegie Endowment for International Peace, 1942, pp. 113.

3. Sobre a contribuição, já no século XII, do Papa Alexandre III ao princípio da liberdade dos mares, vide: VALERY, Le Pape Alexandre III et la Liberté des Mers. RGDIP, pp. 240/251.

4. Estudios de Historia y Doctrina del Derecho Internacional, Madrid, Instituto de Estudios Políticos, 1964, p. 220.

5. Vide Marcelo Caetano, Introdução, in Frei Serafim DE Freitas, do Justo Império Asiático dos Portugueses, Lisboa, Instituto de Alta Cultura, 1960, vol. I, p. 9. AmILCAR Marchevini, Liberdade dos Mares, Rio de Janeiro, 1925, pp. $10 / 34$.

6. Valladão, Haroldo, Democratização e Socialização do Direito Internacional, Rio, Livraria José Olympio, 1961, p. 20.

7. Cf. Perels, Manuel de Droit Maritime International, Paris, 1884, pp. 162/163; De Louter, Le Droit International Public Positif. I, Oxford: Imprimerie de l'Université, 1920, pp. 377/378; LA Pradelle, Le Droit de l'Etat, op. cit., p. 269. 
Da diretriz oposta haviam participado, contudo, na segunda metade do século XV e no século XVI, os soberanos da Inglaterra. Recordem-se a respeito as palavras da rainha Isabel ao embaixador da Espanha que protestara contra as expedições de DRAKE no mar das Antilhas ${ }^{8}$.

Através dessas vicissitudes e controvérsias, que dinamizaram povos e continentes, pode-se dizer com ALBERTo ULLOA que "el descubrimiento de América fue el origen del debate sobre la libertad de los mares" 9 .

Solucionou-se, em fins do século XVII, como se sabe, a questão do domínio dos mares em favor da tese de Grócro, por motivos de ordem não apenas jurídica senão também política. Substituiu o domínio português e espanhol nos mares a Inglaterra que não mais motivos encontrara para continuar a defender as fórmulas eruditas e falazes de SELDEN ${ }^{10}$.

Ao mesmo tempo que declinava a polêmica sobre a liberdade dos oceanos, adquiria consistência, em toda a parte, a noção do mar territorial. Desde o começo do século XVIII - observa ZELLER ${ }^{11}$ - essa noção se revelou enfim triunfante na teoria e na prática internacionais. Em contraposição, se afirmava, triunfante, a noção e a prática do alto-mar.

Tomando por base o fenômeno do descobrimento e o seu influxo no direito das gentes, observa ANDRES A. ARAMBURU MENCHACA ${ }^{12}$ não ser estranho que a América tenha sido "la iniciadora de la reforma del Derecho del Mar y que en su seno hayan tenido lugar las principales iniciativas políticas así como las más elaboradas formulaciones jurídicas...". Desde a sua descoberta, o continente se encontrava fadado a estimular o desenvolvimento das normas e instituições maritimas, o que de fato ocorreu, por motivos culturais, políticos, psicológicos, econômicos, geográficos, tecnológicos, estratégicos, com projeção singular e marcante, sobretudo na parte que se convencionou chamar de América Latina.

8. Higgins and Colombos, International Law of the Sea, $3 .^{2}$ ed. rev., 1954 , pp. $42 / 43$.

9. Régimen Jurídico del Mar. Cursos Monográficos, tomo III, Academia Interamericana de Derecho Internacional y Comparado.

10. GarCIA ARIÁs, Historia, op. cit. pp. 186/188 - Doc. A/CN.4/32. Memorandum présenté par le Secrétariat des Nations Unies, YILC 1950-II, p. 69.

11. Les Temps Modernes, II, Histoire des Relations Internationales, Paris, Hachette, 1955, p. 159.

12. "La Costumbre y la Delimitación de los Espacios Marítimos en el Continente Americano", junio 1973, dact., p. 2. 


\section{A Codificação do Direito do Mar}

Assentou-se $o$ direito do mar clássico em práticas oriundas de Estados litorâneos, o mais das vezes europeus, providos de importantes frotas mercantes e militares ${ }^{13}$. Essas práticas, através de processo lento e complexo, se corporificaram gradualmente em costumes internacionais. Baseado nesta fonte de direito, que a doutrina sistematicamente explicitava, definiu-se o direito do mar através de sucessivas Conferências de Codificação, a começar pela de Haia de 1930, de competência adstrita de início ao regime das águas territoriais e ampliada mais tarde a outras áreas marítimas. Após a inoperância dessa reunião, que a Sociedade das Nações promovera, coube à Conferência de Genebra de 1958 completar etapa subseqüente do processo de codificação. Foi a primeira das reuniões convocadas sob a égide das Nações Unidas. Revestiu ela de forma convencional o direito do mar através de quatro acordos: sobre mar territoral e zona contígua; sobre alto-mar; sobre conservação dos recursos biológicos do mar; e sobre plataforma continental. Foram resultados sem dúvida positivos mas incompletos. Manteve-se um sistema de distribuição de espaços marítimos que, escudado na invocação de normas consuetudinárias, conservava a hegemonia econômica e estratégica das potências navais exercidas na amplitude do alto-mar. Demarcou-se de forma alternativa mas ambígua o limite exterior da plataforma continental permitindo ao Estado costeiro respectivo distendê-lo em função de sua capacidade tecnológica. Ficaram, outrossim, sem solução, dois problemas nucleares - o da largura do mar territorial e dos limites das zonas de pesca - os quais foram confiados, embora inutilmente, ao exame da segunda Conferência das Nações Unidas sobre Direito do Mar, realizada em 1960.

Com o passar dos meses se tornou patente que os tratados de Genebra, de 1958, se mostravam omissos em relação às questões oriundas do desenvolvimento científico e técnico e da exploração dos fundos oceânicos e quanto à conveniência de se instituir uma gestão racional dos meios marinhos. Não é de estranhar que reduzido número de Estados se vinculasse a esses

13. Cf. Thibaut, Françoise. L'Amérique Latine et l'évolution du droit international de la mer, RGDIP, 1971, pp. 742-758; QUÉNEUDEC, Jean-Pierre, "La Remise en Cause du Droit de la Mer", Actualités du Droit de la Mer, Colloque de Montpellier, Paris, Pedone, 1973, pp. 33-41; Bustamante Y Rivero, José Luis. La Doctrina Peruana de las 200 Millas, Lima, P.A. Villanueva, 1963. 
tratados: apenas 49 em relação à Convenção sobre Alto-Mar e sobre a Plataforma Continental; e 41 e 32 Estados, respectivamente, em relação às Convenções sobre Mar Territorial e sobre a Pesca e Conservação dos Recursos Biológicos do Mar. Ampliando-se, desde a assinatura desses acordos, a composição da sociedade internacional, que passou a abranger cerca de centena e meia de Estados, verifica-se que apenas um terço deles se vinculara juridicamente a essas convenções, das quais a última parece ter encontrado menor grau de aceitação, pois só entrou em vigor a 20 de março de 1966, enquanto a Convenção sobre Alto-Mar vigorava desde 1962 e as sobre Mar Terri. torial e Plataforma Continental desde 1964.

Em decorrência de oposição a esses tratados, ou das lacunas neles subsistentes assim como do aumento constante de capacidade dos navios estrangeiros, alguns Estados - o mais das vezes latino-americanos - passaram a adotar medidas unilaterais visando a estabelecer a delimitação do mar territorial e das zonas de pesca assim como direitos preferenciais, em conformidade com interesses próprios ou regionais.

Costuma-se atribuir ao surpreendente progresso tecnológico das últimas décadas, susceptível de ensejar a exploração do relevo submarino subseqüente à plataforma continental, e o receio de que os fundos oceânicos se submetessem a soberanias nacionais e se convertessem em centro de competições acirradas, as principais razões da proposta apresentada no mês de setembro de 1967, perante a Assembléia Geral das Nações Unidas pelo Embaixador ARVID PARDo, delegado de Malta. Aprovada a inclusão de novo tema na agenda da XXIIa. sessão da Assembléia Geral, que então se iniciava, foi a seguir criado Comitê Especial, composto por 35 membros, para estudar a utilização, com fins pacíficos, dos fundos marítimos e oceânicos situados fora dos limites da jurisdição nacional (resolução 2340-XXII) ${ }^{14}$. A 21 de dezembro de 1968, a Assembléia Geral aprovou as resoluções 2467 A, B, C e D (XXIII), pelas quais se estabeleceu a Comissão sobre a Utilização com Fins Pacíficos dos Fundos Marítimos e Oceânicos situados fora dos limites da Jurisdição Nacional. Integrada, inicialmente, por 12 Estados-membros, foi a Comissão ampliada, sucessivamente, de sorte a abranger 86 e finalmente 91 Estados. Ficou essa Comissão incumbida pelas resoluções 2750 A, B e C (XXv), de 17 de dezembro de

14. Sobre o histórico e competência do Comitê Especial, ver Voelckel, Michel. "L'Utilization du Fond de la Mer", AFDI, 1968, pp. 720-721; LÉvy, Jean-Pierre. La Troisième Conférence sur le Droit de la Mer, AFDI, 1971, pp. 784-797. 
1970, de promover os trabalhos preparatórios de nova conferência sobre Direito do Mar, cuja convocação as mesmas resoluções haviam previsto para 1973. Com esse objetivo, a Comissão, após uma série de reuniões em New York e em Genebra, apresentou nesse mesmo ano à Assembléia Geral um relatório sobre suas deliberações, inclusive a documentação respectiva, material esse finalmente remetido a exame da Terceira Conferência das Nações Unidas sobre Direito do Mar, a qual acabou se realizando em data posterior à inicialmente prevista ${ }^{15}$.

A proposta do governo de Malta se referira especificamente à inclusão do seguinte tema: "Declaração e Tratado relativo à reserva exclusiva para fins pacíficos do fundo do mar e do fundo do oceano sob os mares, além dos limites da jurisdicão atual e o uso de seus recursos no interesse da humanidade". Embora se referindo diretamente à problemática dos fundos oceânicos, dependia a análise desse tema da solução dos problemas concernentes à jurisdição de cada Estado, o da deter. minação dos limites exteriores da plataforma continental e o da largura do mar territorial. Seguiu-se gestão dos governos da URSS e dos Estados Unidos sobre a conveniência de convocar uma nova Conferência Geral sobre Direito do Mar para cuidar de três temas (limitação da largura do mar territorial, liberdade de trânsito através dos estreitos internacionais e "interesses especiais dos Estados ribeirinhos no alto-mar"). Mas a Assembléia Geral aprovou, a 15 de dezembro de 1969, a Resolução $2574 \mathrm{~A}$ por meio da qual se solicitou ao Secretário Geral averiguar as opiniões dos Estados-membros sobre a conveniência de convocar uma Conferência com o seguinte objetivo: "rever os regimes do alto mar, da plataforma continental, do mar territorial e da zona contígua, da pesca e da conservação dos recursos biológicos, especialmente para chegar a uma definição clara, precisa e internacionalmente aceita de zona dos fundos marítimos e oceânicos que se encontrem fora dos limites da jurisdiç̃o nacional, à luz do regime internacional" que se estabeleceria para essa zona. Decidiu a Assembléia Geral, a 17 de dezembro de 1970, convocar a Conferência a qual se relacionou (segundo a Resolucão $2750 \mathrm{C}$, parágrafo 2) com "o estabelecimento de um regime internacional eqüitativo - incluindo um mecanismo internacional - para a área e os recursos do leito do mar e dos fundos oceânicos, e o respectivo subsolo, além dos limites da jurisdição nacional, uma precisa definição da área, e uma série extensa de tópicos pertinentes, inclusive

15. LévY, op. cita. p. 784-828. 
os concernentes aos regimes do alto-mar; plataforma continental, mar territorial (abrangendo a questão de sua largura e a questão dos estreitos internacionais) e zona contígua, pesca e conservação dos recursos biológicos do alto-mar (inclusive a questão dos direitos preferenciais dos Estados ribeirinhos), a preservação do ambiente marítimo (inclusive inter alia a prevenção da poluição) e a pesquisa científica".

Essa relação de temas propostos para a consideração da terceira Conferência das Nações Unidas reclamaria classificação, ordem, sistematização. Daí ter a Assembléia decidido nos termos da mesma Resolução (parágrafo $3^{\circ}$ ) - rever nas reuniões subseqüentes, de 1971 e de 1972, os relatórios da Comissão sobre os Usos Pacíficos do Leito do Mar e do Fundo Oceânico além dos Limites da Jurisdição Nacional.

Como se verifica, o âmbito de competência ratione materiae da Terceira Conferência ultrapassa de muito o das que a precederam. Tem ela jurisdição sobre tópicos especiais não considerados em reuniões anteriores, os quais decorrem, predominantemente, do rápido avanço tecnológico manifestado no decorrer dos anos mais recentes. Esse avanço se reflete na crescente produção do petróleo na plataforma continental, no aperfeiçoamento do sistema de dragagem e coleta dos nódulos do fundo oceânico, no aceleramento da construção dos naviosusinas que concorrem para a intensificação da pesca e acarretam gravíssimos riscos para a preservação dos recursos biológicos do mar. A dizimação dos cardumes, os perigos da poluição, o risco de conflitos oriundos da corrida das grandes potências no encalço dos recursos dos fundos oceânicos, concorrem para reavivar o interesse em torno de tópicos inéditos, ou estudados anteriormente mas submetidos a nova reavaliação política, econômica, estratégica, jurídica, avaliação essa justificável pelo fato de que grande número de novos Estados somente desde recente data alcançou oportunidade de contribuir para o estudo e aperfeiçoamento das normas sobre o direito do mar.

Através do processamento da codificação, a contribuição dos países latino-americanos se fez com o propósito de dinamizá-la em bases de universalidade e de integração do temário.

Opuseram-se eles à proposta conjunta soviético-norte-americana limitada a três temas. A firme posição desses países concorreu para que a codificação ocorra em relação a toda a problemática marítima, o que vem ocorrendo nas negociações e se reflete no sistema normativo global do Texto Integrado Oficioso para Fins de Negociação, publicado a 19 de julho de 1977, quatro dias após o fim da sexta sessão, em New York. 
A Terceira Conferência realizou até agora sete sessões ${ }^{16}$, a última das quais se deu em Genebra, de 28 de março a 19 de maio deste ano, estando a próxima prevista para New York, no período de 21 de agosto a 15 de setembro próximo.

\section{III}

\section{O Princípio da Liberdade dos Mares e a América Latina}

Equívoco supor tenha o chamado novo direito do mar emergido a partir apenas de reação contrária às Convenções de Genebra e em razão das lacunas nelas existentes. Duas dessas convenções, sobre Alto-Mar e sobre Mar Territorial e Zona Contígua, sobretudo a primeira, foram preponderantemente explicitação de normas consuetudinárias e, como tais, expressão de interesses tradicionais de potências, favorecidas com a limitação de direitos soberanos de Estado costeiro e com a garantia de liberdade sobre vastas áreas do alto-mar.

$O$ princípio da liberdade dos mares fora proposto por HuGo Grócio como necessário ao progresso das relações entre os povos. Reportava-se o jurista holandês a condições naturais do uso do mar e ao princípio de não poder ser objeto da propriedade ou domínio o que não pudesse ser objeto de ocupação exclusiva. Seria atentar - asseverou-se, a seguir - contra os interesses da comunidade internacional a sujeição do oceano à soberania deste ou daquele Estado. Tendo surgido em oposição às pretensões hegemônicas de soberania oceânica, a concepção da liberdade dos mares havia sido formulada, pois, como essencialmente negativa. Donde a regra da não interferência dos navios; a proibição de fiscalização de pesca, pelo Estado ribei-

16. Vide inter alia: STEvenson, John R. and OxMAN, Bernard H. The Preparation for the law of the Sea Conference, AJIL, 1974, pp. 1 e segs.; idem, The Third United Nations Conference of the Law of the Sea: the 1974 Caracas Session, AJIL, 1975, pp. 1 e segs.; idem, The Third United Nations Conference on the Law of the Sea: the 1975 Geneva Session, AJIL, 1975, pp. 763-797. OxMan, Bernard H. The Third United Nations Conference on the Law of the Sea: the 1976 New. York Session, AJIL 1977, pp. 247-269; idem, The Third United Nations Conference on the Law of the Sea: the 1977 New York Session, AJIL, 1978, p. 57-82; ThIBAUT, Françoise. L'Amérique Latine et l'Evolution du Droit International de la Mer, RGDIP, 1971, pp. 742-758; idem, Le Continent Américain et la Crise du Droit de la Mer, RGDIP, 1976, pp. 785; Garcia-AMador, F.V. The Latin American Contribution to the Development of the Law of the Sea, AJIL, 1974, pp. 33 e segs.; GANZ, David L. The United Nations and the Law of the Sea. ICLQ, 1977, pp. 1 e segs. 
rinho, além do limite de seu mar territorial; e a proclamação da regra de igualdade de oportunidades em alto-mar, as quais passaram a ser usufruídas, contudo, apenas pelos Estados capazes de se utilizar efetivamente desse espaço. Dessa concepção negativa não se engendrava regime de anarquia jurídica dos oceanos, de vez que se considerava cada navio como vinculado às leis do Estado cujo pavilhão ele conduzisse.

Dessa concepção tradicional resultava, contudo, a implantação de ordenamento jurídico de que se beneficiavam apenas as potências marítimas. Embora fosse em tese o alto-mar susceptível de utilização e de exploração, em nível de igualdade, por todos os Estados, ele o era, de fato, apenas por alguns dentre eles, favorecidos pela posse de navios cada vez mais numerosos e mais pujantes. Quanto ao uso do mar não apenas para trânsito e comunicação mas também para captação de recursos biológicos e minerais, o progresso tecnológico contribuía para ainda mais aumentar as vantagens das potências marítimas cujas teses em prol da manutenção de mares territoriais e largura restrita acabaram por subsistir nas Conferências de Codificação de Haia de 1930 e nas de Genebra de 1958 e 1960.

Postulado básico nas concepções de Grócio era o de serem inexauríveis os recursos do mar: este é "tão vasto que é suficiente para todos os usos que todos os povos podem dele se valer, se eles querem retirar água, pescar ou navegar" 17. Esta noção é reiterada na doutrina tradicional. Está em WoLFF, que precisa: Mare vastum res usus inexhausti est ${ }^{18}$. Também em VATTEL 19. Desde que válido esse postulado, era compreensível se afirmasse que entre as chamadas liberdades do altomar figurasse a liberdade de pesca uma vez que a utilização da mesma não causaria prejuízos a ninguém. Identificada a falsidade do postulado, impunha-se reformular - também por esta razão - o direito do mar tradicional. 0 progresso tecnológico indicou ser urgente essa reformulação. $\mathrm{c}$ que demonstra o uso de navios-usinas providos de instalações frigoríficas, a utilização de instrumentos localizadores de cardumes, o emprego de métodos cada vez mais aperfeiçoados da coleta, em grande quantidade, de recursos biológicos. Tornaram-se cada vez mais conhecidos, por outro lado, os modos de vida, as migrações, as

17. Grocio, Jus Belli ac Pacis, Lib. v. II, c. 3 .

18. WolfF, Jus Gentium Scientifica Pertractatum, § 121 (ed. de 1964, reprodução fotográfica no The Classics of International Law, 1974, p. 46).

19. VAtTEL, Droit des Gens, I, Livre I, Chap. Xxirr, \& 281. 
formas de procriação das espécies ictiológicas, o que ao em vez de concorrer para proteger essas espécies têm, o mais das vezes, contribuído para destruí-las. $O$ aumento da capacidade e do tamanho dos navios, as congestões de tráfego em certas áreas do mar, a exploração crescente dos recursos das águas tanto quanto do solo e subsolo marítimos, a instalação de usinas nucleares, de terminais petrolíferos, de ilhas artificiais, com a correspondente contaminação, tudo tem concorrido para anular as premissas em que se baseava o princípio tradicional da liberdade dos mares.

Após as vicissitudes da independência política, a América Latina se revelou sensível, através da primeira obra de direito internacional que nela se publicou - Principios de Derecho de Gentes, cuja primeira edição remonta a 1832 - à modificação dos pressupostos em que se baseava o direito do mar então vigente. $O$ direito internacional que ANDRÉs BELLo conheceu, como escreve EDUARDo PlazA A., "ya no cuadra exactamente a un mundo nuevo en el que todo está por haver, donde surge diariamente un problema no conocido $\mathrm{y}$, por conseguiente, no resuelto según los moldes clásicos". Esse mundo novo fala nova linguagem. "A ese nuevo lenguage hay que traducir la vieja cultura para que América pueda servise de lo que aquella apportó de constructivo" ${ }^{20}$. Em relação especificamente ao direito do mar, dissentia ANDRÉS BELLO do postulado em que se assentava a doutrina clássica sobre a inexauribilidade dos oceanos, fato digno de realce dada a influência dominante dessa doutrina no começo do século XIX, sobretudo a explicitada em VATTEL ${ }^{21}$, o autor que o jurista latino-americano segue, aliás, "mais de perto e com maior freqüência" ${ }^{22}$, embora com reser$\operatorname{vas}{ }^{23}$.

20. Plaza A., Eduardo. Introducción al Derecho Internacional de Andrés Bello, in Obras Completas de Andrés Bello, I, Caracas, Ministerio de Educación, 1954, p. XVIr.

21. Vattel, op. cit. "Il est manifeste que l'usage de la pleine mer, lequel consiste dans la navigation et dans la pêche, est innocent et inépuisable, d'est-à-dire, que celui qui navique o qui pêche en pleịne mer, ne nuit à personne, et que la mer, à ces deux égards, peut fournir aux besoins de tous les hommes. Or, la nature ne donne point aux hommes le droit de s'approprier les choses don't l'usage est innocent, inépuisable; et suffisant à tous..:"

22. Como observa Eduardo Plaza A. são apenas dois os capítulos em que Bello não cita Vattel: o sétimo da primeira parte relativo àos côñủles e o oitavo da segunda, que trata do comércio marítimo dos neutros. Op. cit., I, 1954. p. XCV.

23. Vide Caldera, Rafael Andrés Bello, Caracas, Biblioteca Popular Nacional, $4 .^{2}$ ed., 1965 , p. 186. 
Não sendo os mares inesgotáveis, diz BELLo, "parece que seria lícito a un pueblo apropiarse los paragens en que se encuentran i que no estén actualmente poseídos por otro" ${ }^{24}$. Teve o jurista latino-americano, pois, segundo já foí assinalado ${ }^{25}$, "una visión sumamente dinámica en lo que respecta a la jurisdicción nacional sobre los espacios marinos, anticipándose en un siglo a las concepciones jurídicas que surgiéron con motivo de haberse admitido la agotabilidad de los recursos marinos". 0 interesse dos juristas latino-americanos sobre 0 direito do mar se acentua desde os primeiros anos de emancipação do Novo Mundo. Quatro anos após a edição dos Principios de Derecho de Gentes, publica-se no Brasil a mais antiga monografia sobre direito do mar, que talvez seja também pioneira na América Latina. Foi José Maria de Avelar Brotero, o mais antigo lente e diretor da Faculdade de Direito de São Paulo, quem a redigiu ${ }^{26}$. Trata-se das Questōes sobre Presas Marítimas (São Paulo, 1836), tema versado, aliás, por BELLo na Parte Segunda, Capítulo V, de seus Principios.

O sistema europeu vigente até o começo de nosso século, no qual se integra o direito clássico do mar, era um direito homogêneo e, ao mesmo tempo, hegemônico. "Não fora afetado durante o século XIX" - lembra TRUYOL Y SERRA - "nem por sua extensão ao continente americano nem pela incorporação do Oriente à vida internacional, pois, num caso e noutro, houve a transposição dos 'standards' ocidentais" ${ }^{27}$. No século atual, porém, os países latino-americanos, dando seqüência à busca de soluções próprias, delineada por BeLlo na primeira metade do século passado, promoveram de modo marcante a revisão do direito do mar, através de processo dialético em que os Estados Unidos da América, mais do que os países europeus, encarnaram a posição antitética ${ }^{28}$. O mesmo sistema sofreu, por outro lado, crise recente em virtude do processo de descoloni-

24. Andrés Bello, Principios de Derecho Internacional, in Obras Completas, op. cit., pp. 55-56.

25. Orrego Vicuña, Francisco. Chile y el Derecho del Mar. Santiago de Chile, Editorial Andrés Bello, 1972, p. 10.

26. MarotTa RANGer, Vicente. Primeiros Escritos sobre Direito Interna. cional no Brasil, in Problemas Brasileiros, outubro de 1977, n. 170, pp. 3-9.

27. L'Expansion de la Société Internacionale au XIX.' et au XX.' siècles, Recueil des Cours, ADI, 1965, p. 158.

28. Aramburu Menchaca, Andres A., op. cit., pp. 14-18. 
zação dos países da África e Ásia ${ }^{29}$. Mas os novos Estados, que emergiram desse processo, acabaram por acompanhar o roteiro pioneiro dos países latino-americanos na renovação do direito do mar tradicional, imbuídos do idêntico propósito de favorecer o desenvolvimento econômico e social de seus respectivos povos ${ }^{30}$. E com base numa posição valorativa e crítica, formulada de maneira serena e construtiva, que os juristas e estadistas latino-americanos, seguindo na esteira da contribuição de ANDRÉS BELLO, vêm exercendo suas funções relevantes em prol do direito do mar e das bases tradicionais em que ele se tem constituído.

29. Cf. Bosc, Robert. Le Tiers Monde dans la Politique Internationale, Paris, Aubier-Montaigne, 1968, pp. 62-68; SerenI, A. P. Les Nouveaux Etats et le Droit International, RGDIP, 1968, pp. 305-322; JENks, W. The Common Law of Mankind, 1958, pp. 63 e segs.; Carrillo Salcedo, Aspectos Doctrinales del Problema de la Universidad del Derecho de Gentes, REDI, 1964, pp. 3 e segs.; FALK, R.A., The New States and International Legal Order, Recueil des Cours, ADI, 1956-II, pp. 7-103; Mc. WhINNEY, Edward. Le Nouveau Droit International et la Nouvelle Communauté Mondiale, RGDIP, 1966, pp. 325-345.

30. Peyroux, Evelyne. Les Etats Africains face aù questions actuelles du Droit de la Mer, RGDIP, 1974, p. 624.

NOTA: Este trabalho terá continuidade no volume 75,1980 e nos subseqüentes. 